\title{
Congenital Glaucoma
}

\author{
Jair Giampani Junior and Adriana Silva Borges Giampani \\ Federal University of Mato Grosso, \\ Brazil
}

\section{Introduction}

\subsection{Terminology, epidemiology and heredity}

Congenital glaucoma is a major cause of blindness in children, despite its low incidence $(1: 10,000 \text { births })^{1}$. This category includes isolated congenital glaucoma (also called primary congenital glaucoma) and glaucomas associated with other developmental anomalies, either systemic or ocular.

Juvenile glaucoma is the term used to designate cases in which the pressure rise develops after the third birthday but before the age of 16 years. ${ }^{2}$ The enlargement of the eye (buphthalmos) is least common, despite the elevated intraocular pressure. Gonioscopy is normal or reveals trabeculodysgenesis. This condition may simulate the primary open-angle glaucoma.

The eyes with primary congenital glaucoma have an isolated maldevelopment of the trabecular meshwork not associated with others developmental ocular anomalies or ocular diseases that can raise intraocular pressure. It's the most common glaucoma of infancy, occurring in about 1: 30,000 live births' .

Primary congenital glaucoma is a bilateral disease in about $75 \%$ of cases, with males accounting for approximately $65 \%$ of cases. ${ }^{2}$ Most cases are sporadic in occurrence, with no evident hereditary pattern. In approximately $10 \%$ in which a hereditary pattern is evident, it generally is believed to be autosomal recessive. Many authors believe the inheritance pattern is polygenic. ${ }^{1}$

\subsection{Pathogenesis}

Clinical evidence supports the theory that the obstruction to aqueous flow, with a resultant increase in intraocular pressure, is located at the trabecular sheets. This obstruction is caused by maldevelopment of the anterior chamber angle, unassociated with any other major ocular anomalies (isolated trabeculodysgenesis). ${ }^{2}$

Clinically, trabeculodysgenesis is characterized by absence of the angle recess, with the iris inserted into the surface of the trabeculum in one of two configurations:2

a. Flat iris insertion: the iris inserts flatly into the thickened trabeculum at or anterior to the scleral spur.

b. Concave iris insertion: is less common. The plane of the iris is well posterior to the normal position of the scleral spur. However, the anterior iris stroma continues upward and over the trabecular meshwork, obscuring the scleral spur and the others angular structures. 


\subsection{Clinical presentation}

Frequently, the first symptoms of primary congenital glaucoma are epiphora, photophobia and blepharospasm. These symptoms occur secondary to the corneal epithelial edema caused by elevated intraocular pressure.

The elevated intraocular pressure also causes an enlargement of the eye (buphthalmos) (Figure 1), mainly at the corneoscleral junction. Stretching of the zonules can cause lens subluxation. ${ }^{3}$

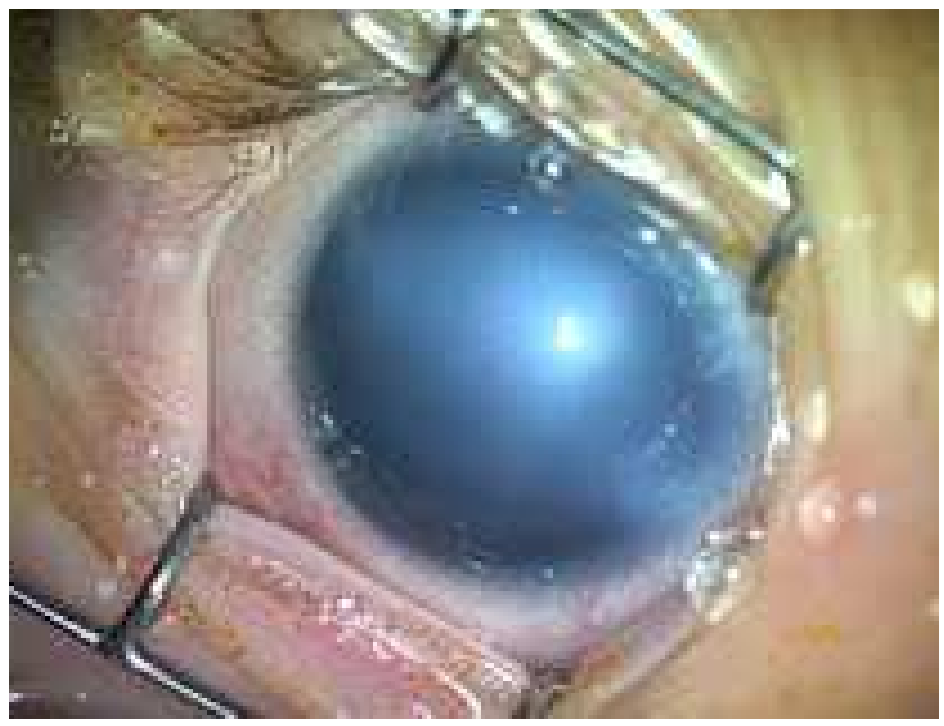

Fig. 1. Buphthalmos and corneal edema (Courtesy Prof. Augusto Paranhos Jr.)

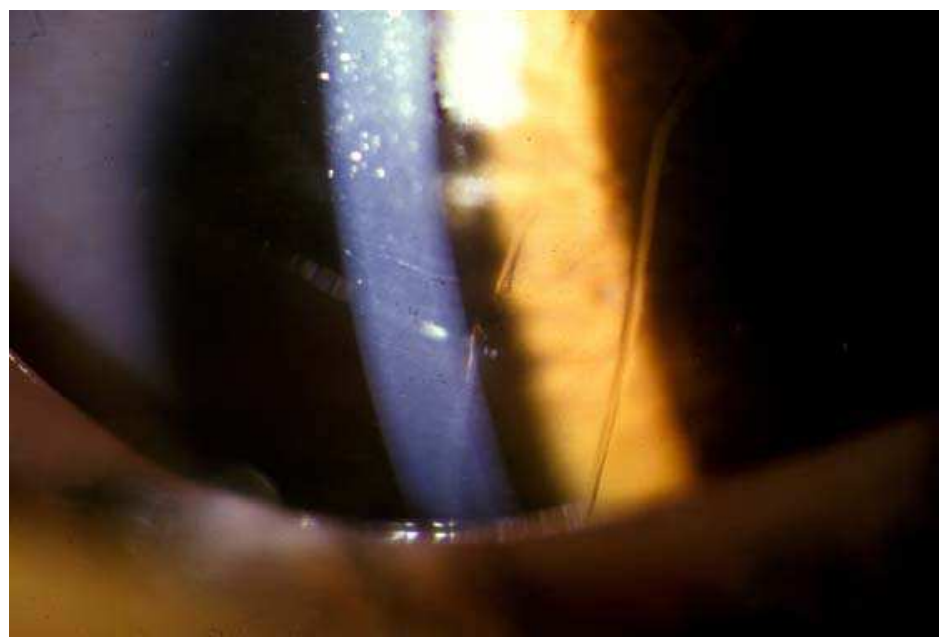

Fig. 2. Haab's striae (Courtesy Prof. Ernst Oltrogge) 
As the cornea stretches, ruptures of the Descemet's membrane allow influx of aqueous into the corneal stroma and epithelium, causing an increase in edema and haze. The breaks in Descemet's membrane (Haab's striae - Figure 2) are single or multiples, and appear as elliptical parallel ridges on the posterior cornea. ${ }^{3}$ The Haab's striae are usually horizontal or oblique in contrast to traumatic Descemet's tears that are vertically oriented. Progressive myopia may occur if the elevated intraocular pressure persists.

Pain is unusual in the older child with glaucoma, unless corneal erosion or ulceration appear.

In contrast to the adult eye, the scleral canal in the infant eye enlarges as part of the generalized enlargement of the globe, and the lamina cribrosa may bow posteriorly, in response to elevated intraocular pressure. Therefore, cup size may be increased from neuronal loss, enlargement of the scleral canal, or both. ${ }^{2}$

\subsection{Initial evaluation and follow-up (Flowchart 1)}

Depending on the patient's age and ability to cooperate, either an office examination or an examination using general anesthesia with intravenous ketamine is required to evaluate the child with glaucoma. ${ }^{3}$

Examination of the corneal diameter should be undertaken first, followed by applanation tonometry, slit lamp examination, gonioscopy and evaluation of the optic discs.

a. corneal diameter should be measured in both vertical and horizontal meridians with calipers. The horizontal diameter is usually easier to measure and more accurate than the vertical, due an excessive corneal limbus stretching in this meridian. A diameter > $12 \mathrm{~mm}$ prior to the age of one year should be viewed with suspicion. ${ }^{4}$

b. Intraocular pressure could be measure with a Goldmann tonometer, Perkins tonometer or Tono-Pen. Elevated intraocular pressure by itself, unless extreme, is not sufficient to confirm a diagnosis of glaucoma. It is necessary to depend on signs such as increased corneal diameter and corneal thickness, increased cup-disc ratio or evidence of trabeculodysgenesis to confirms the diagnosis.

The normal intraocular pressure in children under general anesthesia is unknown. Some authors consider glaucoma suspects children with IOP above $14 \mathrm{~mm} \mathrm{Hg.4}$ Nevertheless, its important to remember the major of anesthetics reduces the intraocular pressure, while ketamine may increase intraocular pressure. 4

c. The slit lamp examination may reveal corneal edema, haze and ruptures of the Descemet's membrane (Haab's striae). The anterior chamber is deep, with iris hypoplasia sometimes showing the iris pigment epithelium. ${ }^{4}$ Stretching of the zonules can cause lens subluxation.

d. Gonioscopy should be performed with a Koeppe lens or one of the others goniolenses. Gonioscopy of the eye with congenital glaucoma reveals an anterior insertion of the iris directly into the trabecular meshwork. This insertion most commonly is flat (Figure 3), although a concave insertion may also be seen. The level of the iris insertion may vary at different areas of the angle. No pigment band is present, but a thin section of ciliary body can be seen through the thickened trabeculum. The peripheral iris may show a thinning of the anterior stroma.

e. Opthalmoscopy of the eye with congenital glaucoma may be impossible in some cases, due corneal edema and/or haze. The infant glaucomatous cup usually has a configuration different from that of an adult glaucomatous cup. It's more commonly round, steep walled and central. ${ }^{1}$ The cup tends to enlarge circumferentially with progression of the glaucoma. In the very young, cupping can decrease after intraocular 
pressure is brought under control. To provide records for future comparison, it is best to take photographs of the optic nerve head, whenever possible.

f. Auxiliary exams: the measurement of axial length by A-scan ultrasonography has been recommended by some authors for routine use in the diagnosis and follow-up of congenital glaucoma. ${ }^{4}$ The eyes with congenital glaucoma commonly present an elevated axial length due the elevated intraocular pressure.

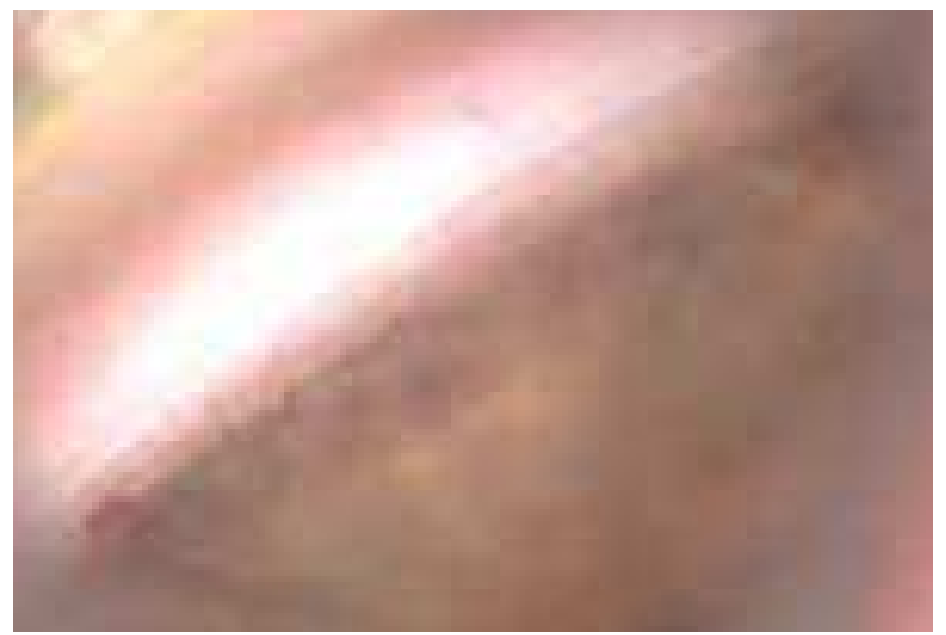

Fig. 3. Gonioscopy showing the flat iris configuration (Courtesy Prof. Augusto Paranhos Jr.)

The standard automated perimetry may be useful in the diagnosis and follow-up of congenital glaucoma patients above 7 years old. ${ }^{4}$ Unfortunately, there is not adequate software to analyze children in any automated perimeters.

Patients with congenital glaucoma require follow-up examinations for life. The IOP measure, ophthalmoscopy and visual field analysis, when it is possible, must be realized at least every 3 to 6 months, depending the glaucoma severity. The long-term prognosis for intraocular pressure control in successfully treated cases of congenital glaucoma appears excellent. However, the visual outcome and IOP control in unsuccessfully treated cases after one or two surgical procedures, may be poor.

\subsection{Differential diagnosis}

Many conditions may confuse the primary congenital glaucoma diagnosis and present corneal edema, epiphora, corneal enlargement or elevated intraocular pressure. ${ }^{2}$

a. Cloudy cornea at birth: trauma with breaks in the Descemet's membrane, intrauterine rubella, metabolic disorders (mucopolysaccharidoses) and congenital hereditary endothelial dystrophy.

b. Corneal enlargement: megalocornea and high myopia.

c. Epiphora: congenital obstruction of the nasolacrimal duct.

d. Secondary infantile glaucoma: trauma, ectopia lentis, uveitis, tumors, retinopathy of prematurity and persistent hyperplastic primary vitreous, corticosteroid-related glaucoma. 


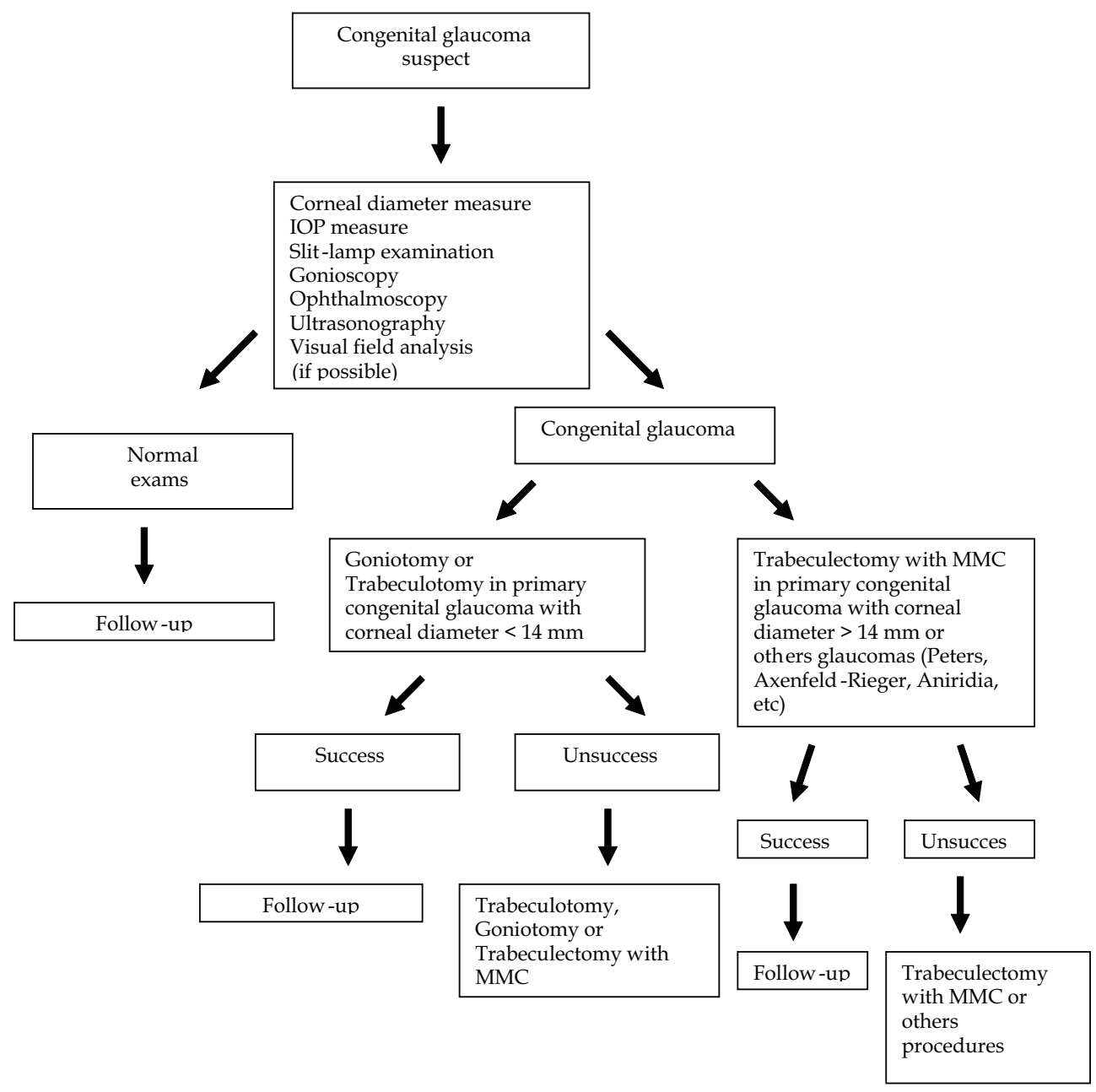

Flowchart 1. Congenital glaucoma management and follow-up

\subsection{Management}

Congenital glaucoma is essentially a surgical disease, in which surgery must be performed as early as possible. Goniotomy and trabeculotomy are usually the first procedures of choice (Flowchart 1). ${ }^{1}$ Both are safe and have a low incidence of complications. Factors that can decrease the success rate of initial trabeculotomy are the association of CG with others ocular anomalies (Peters, Sturge-Weber, Aniridia, etc.) and a corneal diameter of $>14 \mathrm{~mm} .^{2}$ Usually, trabeculectomy is the option when previous goniotomies or trabeculotomies failed. Glaucoma drainage implants, non-penetrating surgery and cyclodestructive procedures are options also.

Surgery is preferred for several reasons, including problems with compliance to medications, lack of knowledge about the systemic effects of medications in the infant and poor response 
to clinical treatment in infants. Moreover, surgery has a high success rate and low incidence of complications.

Neither goniotomy nor trabeculotomy should be performed by surgeons inexperienced with the procedure. The first operation, whether goniotomy or trabeculotomy, has the greatest chance of success.

a) Goniotomy

Goniotomy is a very safe procedure when performed skillfully. Goniotomy is commonly the procedure of choice when corneal transparency permits adequate visualization of the angle (Figures 4 and 5). Corneal clouding only rarely prevents performance of goniotomy, particularly if cloudy epithelium is removed. 4

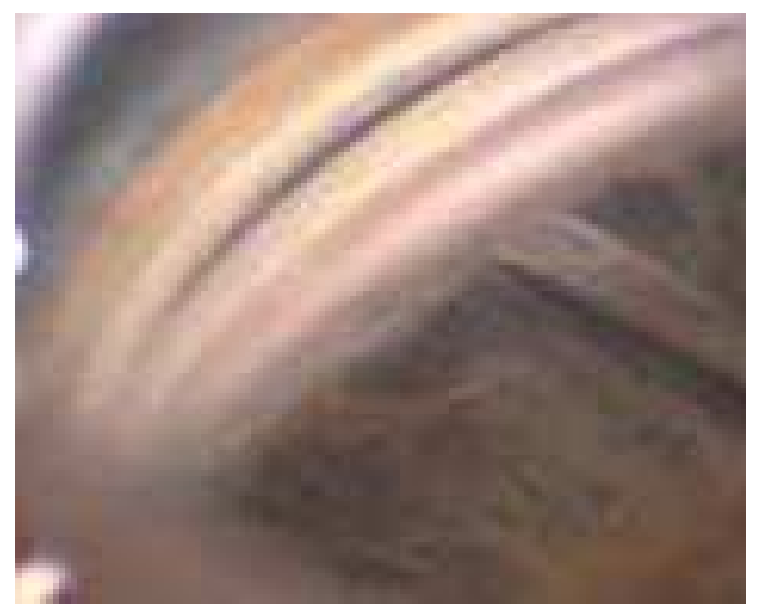

Fig. 4. Goniotomy (Courtesy Prof. Augusto Paranhos Jr.)

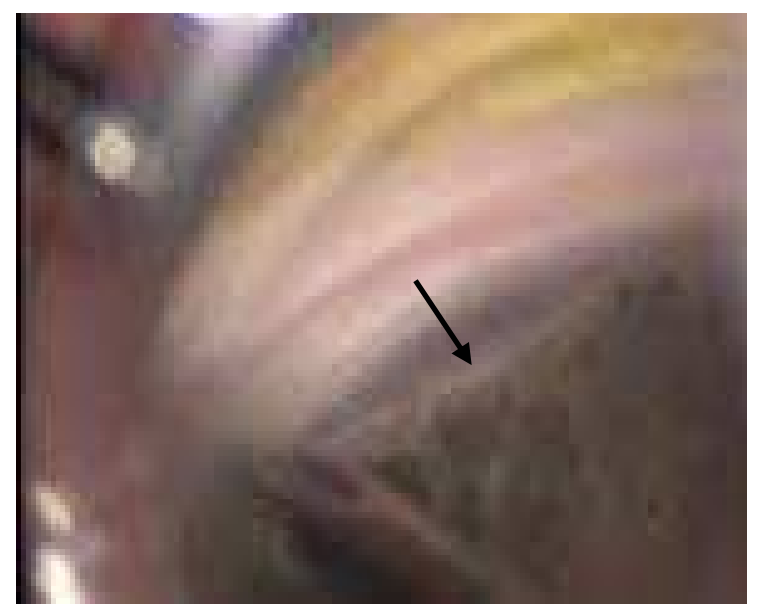

Fig. 5. Goniotomy: see the iris configuration after incision (arrow) (Courtesy Prof. Augusto Paranhos Jr.) 
It is necessary a goniolenses, like the Worst lens, to performed the goniotomy through direct visualization of the angle.

Shaffer ${ }^{5}$ reported in a study on a series of 287 eyes, one or two goniotomies cured $94 \%$ of patients diagnosed between 1 month and 24 months of age. Goniotomy is unlikely to be effective if corneal diameter exceeds $14 \mathrm{~mm}$, since in such eyes the Schlemm's canal is obliterated. $^{2}$

\section{b) Trabeculotomy}

Trabeculotomy may be necessary if corneal clouding prevents visualization of the angle (Figures 6 and 7). It was described initially by Burian in 1964, and posteriorly improved by Harms and Machensen. ${ }^{4}$

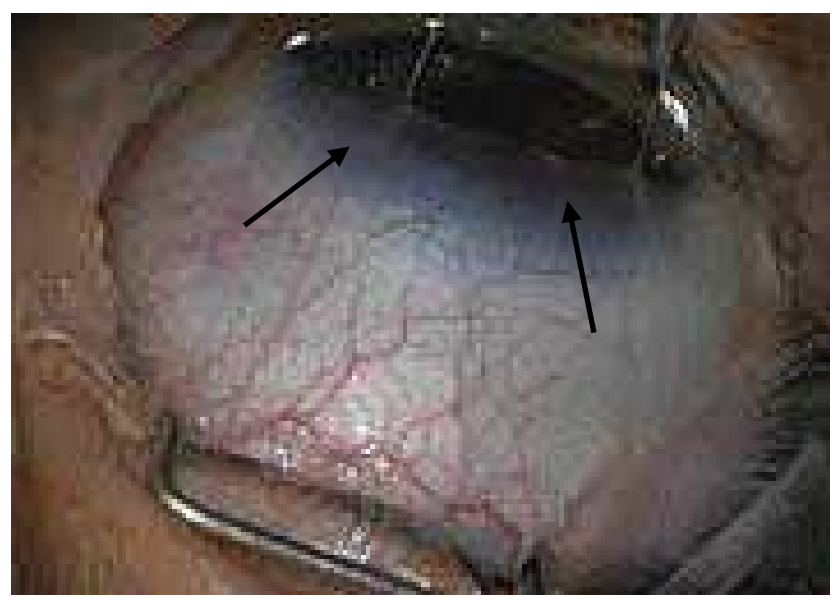

Fig. 6. Trabeculotomy: see the enlargement of the corneoscleral junction (arrows) (Courtesy Prof. Augusto Paranhos Jr.)

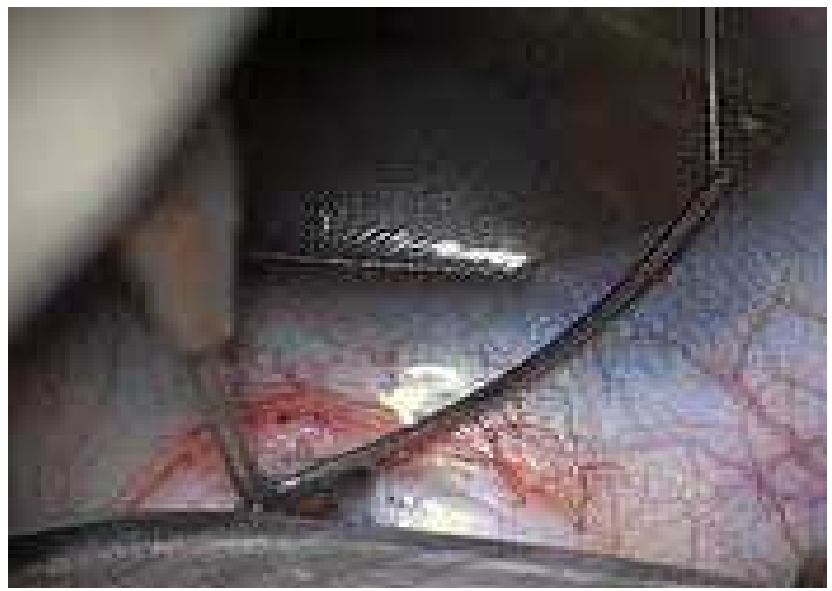

Fig. 7. Trabeculotomy: see the trabeculotome position (Courtesy Prof. Augusto Paranhos Jr.) 
Trabeculotomy also has a high success rate, with most studies citing an $80 \%$ to $90 \%$ success rate. ${ }^{6}$ The incidence of complications is low, and includes hyphema, tears in Descemet's membrane, ciclodialysis, iridodialysis and synechiae. ${ }^{3}$

c) Update in trabeculectomy in congenital glaucoma

Usually, trabeculectomy is the option when previous goniotomies or trabeculotomies failed. It has been reported that trabeculectomy without adjunctive antimetabolites in pediatric patients (less than 18 years of age) has a successful outcome in $30 \%$ to $50 \%$ of cases. ${ }^{7-9}$ The $50 \%$ rate is from a study with relatively short follow-up (mean 15.5 months). ${ }^{7}$ Studies with longer follow-up report a success rate of $30 \%$ to $35 \%$. $8-9$

Mitomycin C (MMC) is a more potent inhibitor of fibroblast proliferation comparing to 5fluorouracil, and can be used intraoperatively, making it an attractive alternative for children in which previous surgery have failed. Clinical studies comparing the two antifibrotic agents have demonstrated a greater success rate and a greater degree of IOP with MMC.10-13

Susanna et al. ${ }^{14}$ had an overall success rate of $67 \%$ with a mean follow-up of 17 months in a series of 56 patients (79 eyes) with primary congenital glaucoma or developmental glaucomas underwent to trabeculectomy and adjunctive MMC. This success rate is better than it described for Giampani Jr et al. ${ }^{15}$ (55.26 \%), probably because their longer follow-up (61.16 months).

Beck et al. ${ }^{16}$ described a success rate of $58 \%$ after 24 months follow-up, although they had a large number of aphakic patients and a mean age of 91.2 months (7.6 years old). Sidoti et al. 17 showed a success rate of $59 \%$ in a case series with 29 eyes, with a mean follow-up time of $25.1+/-16$ months. Giampani Jr et al. ${ }^{15}$ described a success rate of $90.2 \%$ at 24 -month, $78.7 \%$ at 36 -month, $60.7 \%$ at 48 -month and $50.8 \%$ at 60 -month.

A very high success rate (95\%) was described by Mandal et al. in a series of 19 mitomycin C trabeculectomies (Table 1). ${ }^{18}$ However, this study had only one patient under 1 year of age, which may be an important factor in that study's superb success rate. Miller and Rice also showed a better prognosis for surgeries performed in older children. ${ }^{19}$

Susanna et al. noted no changes in success rate when comparing eyes that had previous glaucoma surgery with those eyes that had no prior surgery. ${ }^{14}$ They suggested that the results of the group that had no prior glaucoma surgery were skewed by the presence of more eyes with poor prognoses, namely Axenfeld-Rieger syndrome, Sturge-Weber syndrome, and Aniridia. Beck et al. ${ }^{16}$ demonstrated a lower success rate for the group that had prior glaucoma surgery (55\% compared with $70 \%$ ), but without statistically significant difference. Giampani Jr et al. observed that the success rate was also higher in the group with no previous glaucoma surgery $(64.28 \%$ compared with $51.21 \%)$, but without statistically significant difference also $(\mathrm{p}=0.32) .{ }^{15}$

Endophthalmitis is a major complication associated with trabeculectomy, and it has been reported in children who have had trabeculectomy with mitomycin C. ${ }^{20}$ Giampani Jr et al. observed eight eyes with endophthalmitis in a total of 164 operated eyes (4.88\%). ${ }^{15}$ Beck and associates ${ }^{16}$ reported a higher endophthalmitis rate $(8 \%)$, while Susanna et al ${ }^{14}$ reported one case in 79 eyes, and Wallace and associates ${ }^{21}$ noted one case in a series of 16 eyes. Mandal et al. had no cases of endophthalmitis in 19 eyes. ${ }^{18}$ Sidoti et al. described the highest infection complication rate of any reported series ( $10 \%$ of blebitis and $7 \%$ of endophthalmitis). ${ }^{17}$ Probably, the higher MMC concentration utilized for them $(0.5 \mathrm{mg} / \mathrm{mL})$ explained, in part, that rate. In adults, the endophthalmitis rate after use of antimetabolites range from $2 \%$ to $9 \% .22-24$ 
Others complications, like overfiltration and hypotony maculopathy, are rarely observed after trabeculectomy with adjunctive mitomycin $\mathrm{C}$ in primary congenital glaucomas. ${ }^{15}$

\begin{tabular}{|l|c|c|}
\hline \multicolumn{1}{|c|}{ Authors } & Success rate (\%) & Follow-up (months) \\
\hline Giampani Jr. et al. ${ }^{15}$ & $55.26 \%$ & 61.16 \\
\hline Beck et al ${ }^{16}$ & $58 \%$ & 24 \\
\hline Sidoti et al. ${ }^{17}$ & $59 \%$ & 25.1 \\
\hline Susanna et al. ${ }^{14}$ & $67 \%$ & 17 \\
\hline Mandal et al. ${ }^{18}$ & $95 \%$ & 19.52 \\
\hline
\end{tabular}

Table 1. Trabeculectomy success rate in congenital glaucoma

a) Aqueous drainage device surgery in congenital glaucoma

Aqueous drainage devices were recommended in congenital glaucoma treatment when others procedures, like goniotomy, trabeculotomy and trabeculectomy failed (Figures 8 and 9). Unfortunately, the long-term successful rate is generally poor. ${ }^{4}$

O’Malley et al. described, in a chart review including 38 eyes with congenital glaucoma, a success rate about only $42 \%$ after 10 years follow-up. ${ }^{25}$ Khan et al. observed, in a small sample of 11 eyes with congenital glaucoma, a success rate of $90.9 \%$ after 2 years follow-up, using the silicone Ahmed valve. ${ }^{26}$ A long -term study using this device is needed to determine whether or not silicone as a good option in congenital glaucoma patients.

The most common complications in congenital glaucoma patients are tube malpositioning with corneal touch, tube exposure, endophthalmitis, retinal detachment and ocular motility abnormalities. ${ }^{27}$

b) Cyclodestructive procedures

Cyclocryotherapy may be used when repeated surgery to improve outflow has failed. Transscleral cyclophotocoagulation has been used to produce thermal damage to the ciliary body and processes to decrease aqueous production. This method can have the advantage of less pain and inflammation than with cyclocryotherapy, but it still usually is reserved for cases in which surgery to improve aqueous outflow has failed. ${ }^{3}$

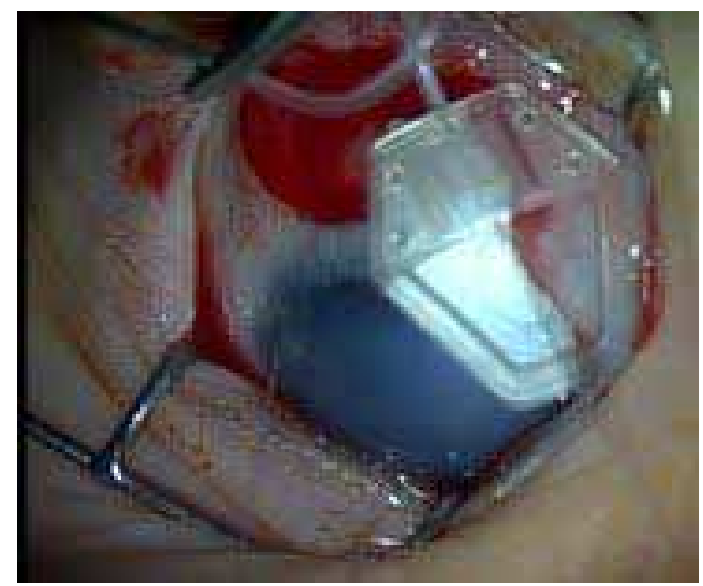

Fig. 8. Ahmed valve in primary congenital glaucoma (Courtesy Augusto Paranhos Jr.) 


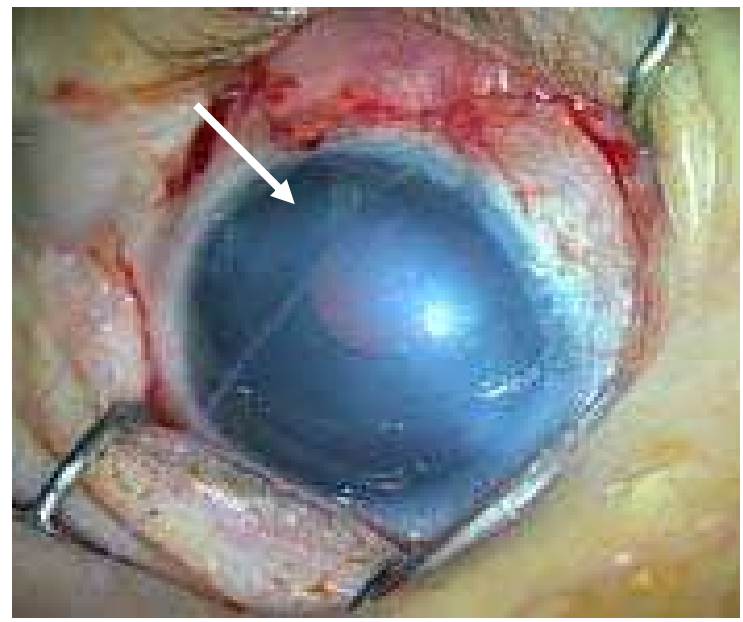

Fig. 9. Ahmed valve: see the tube in the anterior chamber (arrow) (Courtesy Augusto Paranhos Jr.)

c) Novel surgical procedures

Viscocanalostomy was recently described as a novel surgical procedure to improve the aqueous outflow in congenital glaucoma patients. Kay et al. reviewed 39 eyes that underwent dilation and probing of Schlemm's canal and viscocanalostomy. Surgical success was achieved in 27 of 39 eyes (69\%) with an average follow-up of 22 months. In patients without history of previous surgery and the diagnosis of primary congenital or juvenile glaucoma, surgical success was achieved in 17 of 19 eyes (89\%) with an average follow-up of 20 months. There were no serious surgical complications associated with this procedure in this study. 28

Nouredin et al. studied the effectiveness of viscocanalostomy in patients with primary congenital glaucoma and compared it with trabeculotomy ab externo. Eight patients with bilateral primary congenital glaucoma were enrolled in the study. After establishing the diagnosis, the more severely affected eye was randomly selected to undergo either trabeculotomy ab externo or viscocanalostomy, whereas the second eye underwent the other surgery 2 weeks after the first. The mean standard deviation (SD) follow-up period was 12.5 (1.86) months. A drop in IOP was noted in both groups at week 1, month 6 and at the last follow-up visit $(\mathrm{p}<0.001) .{ }^{29}$ Viscocanalostomy proved to be as effective as trabeculotomy ab externo in lowering IOP in this small sample study. Nevertheless, long-term follow-up studies using viscocanalostomy are required to determine it as a good option in congenital glaucoma patients.

\section{Glaucomas associated with congenital anomalies}

\subsection{Iridocorneal dysgenesis}

Iridocorneal dysgenesis consists of overlapping rare congenital disorders involving the cornea and the iris, some of which may be associated with glaucoma. These conditions occur as a result of abnormal neural crest cell development and are: Axenfeld-Rieger syndrome, Peters anomaly and aniridia. ${ }^{30}$ 


\section{a) Axenfeld-Rieger syndrome}

This syndrome is characterized by a mesodermal dysgenesis with different degrees of presentation. The Axenfeld anomaly shows a prominent and anteriorly displaced Schwalbe's line (called posterior embryotoxon) onto which are attached strands of peripheral iris tissue (Figure 10). The secondary glaucoma is rare in this condition. On the other hand, the Rieger anomaly is an autosomal dominant condition with a high degree of penetrance, where mutations in PITX2 and FOXC1 genes were described. ${ }^{31}$ Involvement is usually bilateral but not always symmetrical. The slit-lamp biomicroscopy may show posterior embryotoxon, iris stromal hypoplasia, corectopia, pseudopolycoria and ectropion uveae (Figure 11). The gonioscopy in mild cases shows Axenfeld anomaly. In severe cases, broad leaves of the iris stroma adhere to the corneal anterior to Schwalbe's line. Glaucoma develops in about 50\% of cases, usually during the early childhood. ${ }^{4}$

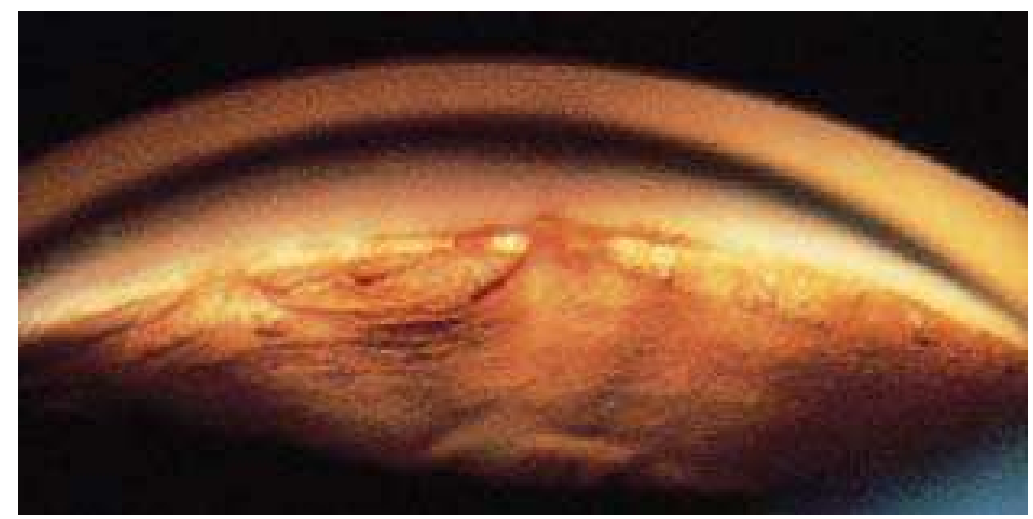

Fig. 10. Posterior embryotoxon onto which are attached strands of peripheral iris (Courtesy Prof. Ernst Oltrogge)

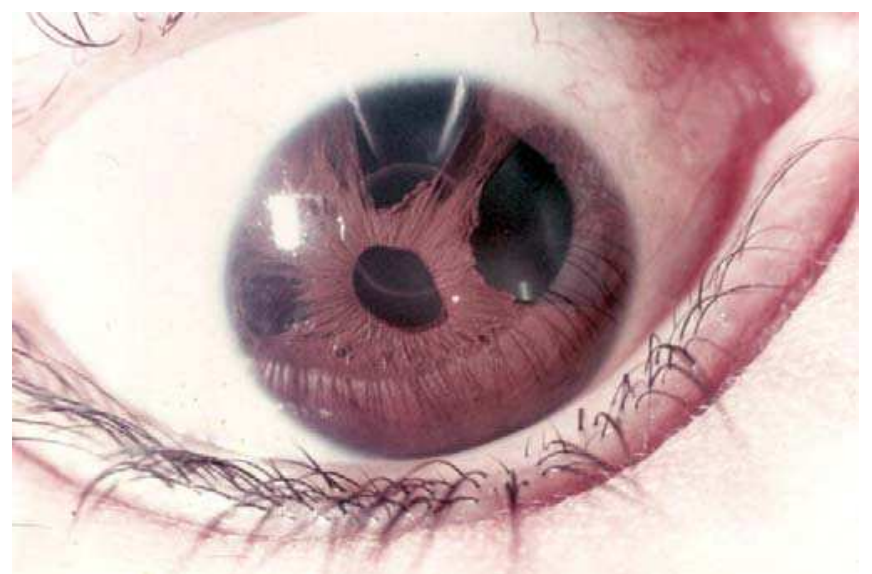

Fig. 11. Rieger's anomaly showing corectopia and pseudopolycoria (Courtesy Prof. Celso Antonio de Carvalho) 
The Rieger's syndrome consists of Rieger's anomaly in association with systemic malformations, like hypodontia (a decrease in the number of teeth), microdontia (a decrease in the teeth size) and facial malformations, including hypoplasia of the maxilla, a broad flat nasal bridge, telecanthus (a lateral displacement of the medial canthus) and hypertelorism (an increased distance between the bony orbits). ${ }^{30}$ Others anomalies include redundant paraumbilical skin.

Some authors proposed the term Axenfeld-Rieger syndrome for all clinical variations within this spectrum of developmental disorders. ${ }^{4}$

The glaucoma treatment is surgical in the most cases of these disorders. Options of incisional surgery include goniotomy, trabeculotomy and trabeculectomy. The first two procedures have been used in infants with limited success. Trabeculectomy with adjunctive mitomycin $C$ is the surgical procedure of choice for most patients with glaucoma associated with Axenfeld-Rieger syndrome. The long-term successful rates, however, are poor.14,15

\section{b) Peters anomaly}

This anomaly is characterized by a congenital central cornea leukoma associated with a defect in the corresponding posterior stroma and Descemet's membrane, with synechiae extending from the central iris to the periphery of the corneal opacity (Figure 12). ${ }^{32}$ Some patients may have a central keratolenticular adherence with shallowing of the anterior chamber, whereas others may have an anterior polar cataract. A variety of less commonly associated ocular findings include microcornea, microphthalmia, cornea plana, aniridia, sclerocornea and corectopia. An association between Peters anomaly and the systemic alterations seen in Axenfeld-Rieger syndrome is not uncommon. ${ }^{4}$

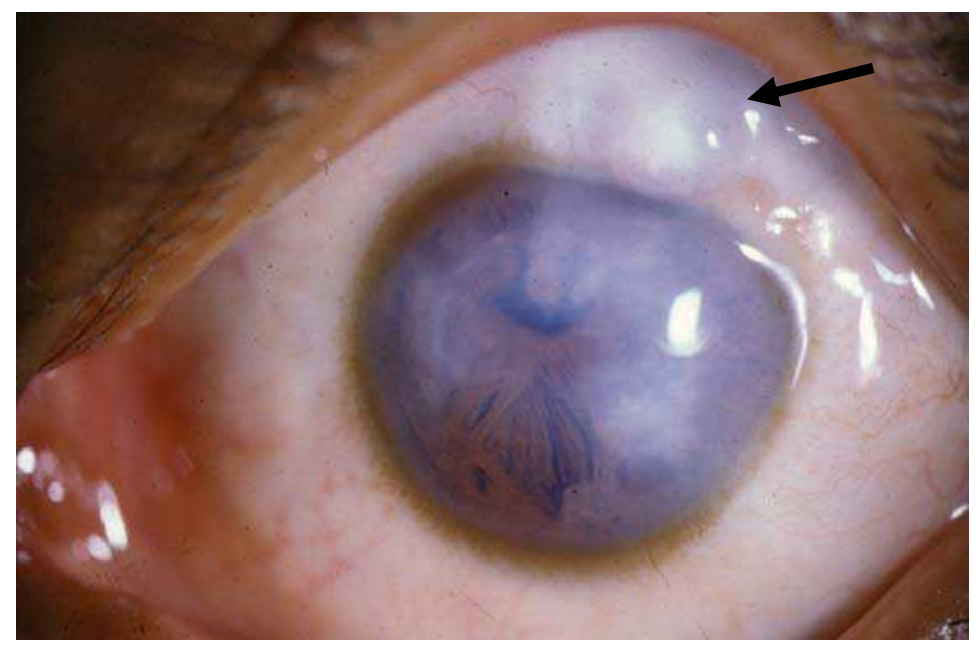

Fig. 12. Peters anomaly after trabeculectomy with MMC (see the bleb - arrow) (Courtesy Prof. Ernst Oltrogge)

Most cases are sporadic, although autosomal recessive inheritance and chromosomal defects have been described. About $80 \%$ percent of cases are bilateral. The pathogenesis involve a defect neural crest cell migration in the sixth to eight weeks of fetal development, during which time the anterior segment of the eye is formed. ${ }^{30}$ 
Glaucoma occurs in $50 \%$ to $70 \%$ of cases. Elevated intraocular pressure unresponsive to topical medications should be treated surgically, before penetrating keratoplasty is performed. Trabeculectomy with use of antimetabolites is the procedure of choice in these cases. ${ }^{32}$ Unfortunately, the long-term visual outcome and glaucoma control are usually poor. 4

\section{c) Aniridia}

It is a bilateral condition with life-threatening associations. It occurs as a result of abnormal neuroectodermal development secondary to a mutation in the PAX6 gene linked to 11p13.30 This gene controls the development of a number of structures, hence the broad nature of ocular and systemic manifestations. The inheritance is autosomal dominant in most cases.

The aniridia is variable in severity, ranging from minimal to total (Figure 13). However, even eyes with total involvement usually show a residual iris tissue in the angle on gonioscopy. Others ocular findings include corneal lesions (leukomas, microcornea and sclerocornea), cataract, aphakia and lens subluxation, foveal hypoplasia, choroidal coloboma and optic nerve hypoplasia. The systemic manifestations include Wilm's tumor, genitourinary anomalies, mental retardation and cerebellar ataxia.

Glaucoma occurs in approximately $2 / 3$ of cases and usually presents in late childhood and adolescence. 4 The intraocular pressure control is usually difficult, and the medical therapy is inadequate in most cases. The surgical procedures, like goniotomy and trabeculotomy, show poor long-term results. The trabeculectomy with adjunctive antimetabolites is the procedure of choice is most cases. However, the long-term results are also disappointing. ${ }^{14-16}$

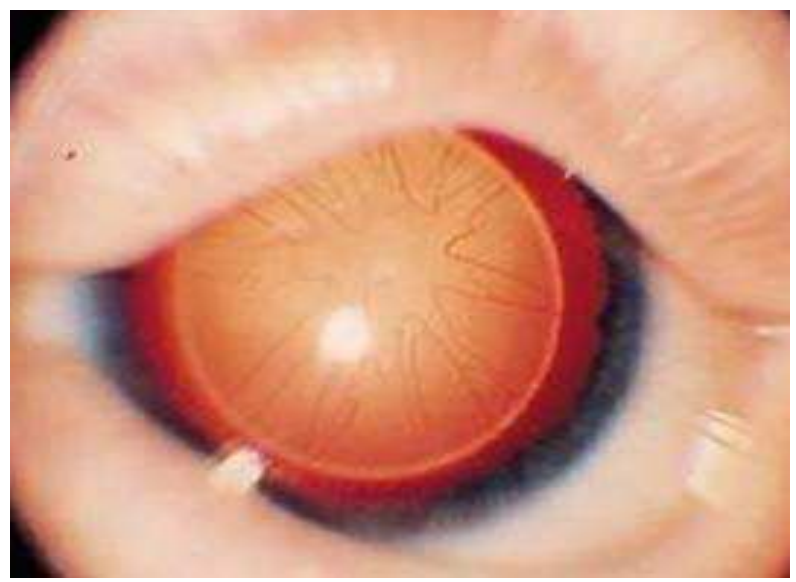

Fig. 13. Total aniridia (Courtesy Prof. Ernst Oltrogge)

\subsection{Phacomatoses}

The Phacomatoses are characterized by the formation of hamartias and hamartomas in the eye, central nervous system, skin and viscera. They are hereditary disorders with variable penetrance and expressivity.

a) Sturge-Weber syndrome

Also called encephalotrigeminal angiomatosis is characterized by facial haemangioma (naevus flammeus -Figure 14), choroidal haemangioma and intracranial meningeal 
angiomata. The haemangioma usually involves the first and second divisions of the trigeminal nerve. The disease has little familial tendency, and no sexual or racial predisposition. Chromosomal abnormalities have been reported in some patients, and the disorder may be a dominant trait with incomplete penetrance. ${ }^{33}$

Glaucoma develops in about $30 \%$ of patients, ipsilateral to the facial haemangioma, especially if the lesion affects the upper eyelid.

The glaucoma pathogenesis involves a trabeculodysgenesis and an elevated episcleral venous pressure. The medical treatment with prostaglandin analogues (enhancing uveoscleral outflow) may be useful in some cases. Nevertheless, surgical approach is necessary in most cases. The goniotomy may be successful in eyes with angle anomalies (trabeculodysgenesis). The combined trabeculotomy-trabeculectomy gives good results in early-onset cases, before the buphthalmos appearing. Surgery always carries a high risk of choroidal effusion and suprachoroidal haemorrhage. Adverse consequences of this may be minimized by performing a posterior sclerotomy before opening the eye. ${ }^{34}$

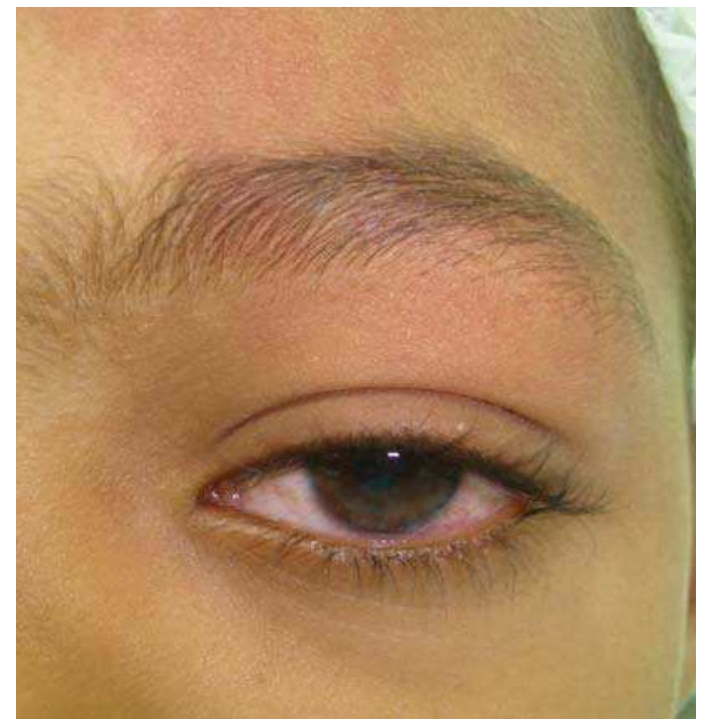

Fig. 14. Naevus flammeus in Sturge-Weber syndrome

\section{b) Neurofibromatosis}

It is a neuroectodermal dysplasia characterized by tumor-like formations (neurofibromas) derived from the proliferation of peripheral nerve elements. The neurofibromas can occur in the central nervous system, central and peripheral nerves, as well in skin and mucus membranes. Inheritance is autosomal dominant with irregular penetrance and variable expressivity. Glaucoma is uncommon, usually unilateral and congenital. Classically, neurofibromatous involvement of the upper lid is present. Glaucoma is present in $50 \%$ of all eyes with plexiform neuroma. ${ }^{4}$

Many mechanisms have been postulated as causes of glaucoma in neurofibromatosis. The elevated intraocular pressure may occur secondary to obstruction of aqueous outflow by neurofibromatous tissue, developmental angle anomaly or angle closure caused by neurofibromatous thickening of the ciliary body or synechiae. 
Many surgical procedures, like goniotomy, trabeculotomy, trabeculectomy and cyclodestructive procedures have been reported for the glaucoma treatment. ${ }^{35}$ However, the overall rate of success of surgery in literature is much lower than that for primary congenital glaucoma. ${ }^{33}$

\section{Secondary infantile glaucoma}

The secondary infantile glaucomas may be associated with non-hereditary congenital diseases, trauma or intraocular tumors. The secondary glaucoma after congenital cataract surgery is usually a disease with poor visual outcome. Fortunately, the modern cataract surgery and the novels topical anti-inflammatory drugs reduced the complications after congenital cataract surgery, like vitreous loss, retinal detachment and glaucoma. Nevertheless, the treatment of elevated intraocular pressure after congenital cataract surgery is usually difficult and a trabeculectomy with adjunctive antimetabolite may be necessary. ${ }^{4}$ Others secondary infantile glaucoma causes include persistent hyperplastic primary vitreous, retrolental fibroplasia, corticosteroid-related glaucoma and retinoblastoma.

\section{References}

[1] Dickens CJ., Hoskins JR HD. Epidemiology and Pathophysiology of Congenital Glaucoma. In The Glaucomas. Ritch R, Shields MB, Krupin T. Mosby, second edition, 729-738; 1996.

[2] Kanski J. J. Primary Congenital Glaucoma. In Clinical Ophthalmology. ButterworthHeinemann, fifth edition, 245-248; 2003.

[3] Dickens CJ, Hoskins JR HD. Diagnosis and Treatment of Congenital Glaucoma. In The Glaucomas. Ritch R, Shields MB, Krupin T. Mosby, second edition, 739-749; 1996.

[4] Betinjane, AJ. Glaucoma Infantil. In Glaucoma. Susanna Jr R. Cultura Médica. 145-179; 1999.

[5] Shaffer RN. Prognosis of goniotomy in primary infantile glaucoma. Trans Am Ophthalmol Soc 80:321; 1982.

[6] Anderson DR. Trabeculotomy compared to goniotomy for glaucoma in children. Ophthalmology 90: 805; 1983.

[7] Beauchamp GR, Parks MM. Filtering surgery in children: barriers to success. Ophthalmology 1979, 86: 170-80.

[8] Inaba Z. Long-term results of trabeculectomy in the japanese: an analysis by life-table method. Jpn J Ophthalmol 1982, 26: 361-73.

[9] Gressel MG, Heuer DK, Parrish II RK. Trabeculectomy in young patients. Ophthalmology 1984, 91: 1242-6.

[10] Katz GJ, Higginbotham EJ, Lichter PR et al. Mitomycin C versus 5-fluorouracil in highrisk glaucoma filtering surgery. Ophthalmology 1995; 102: 1263-9.

[11] Kitazawa Y, Kawase K, Matsushita H, Minobe M. Trabeculectomy with mitomycin. A comparative study with Fluorouracil. Arch Ophthalmol 1991; 109: 1693-8.

[12] Lamping KA, Belkin JK. 5-Fluorouracil and Mitomycin C in pseudophakic patients. Ophthalmology 1995; 102: 70-5.

[13] Prata JA Jr, Minckler DS, Baerveldt G et al. Trabeculectomy in pseudophakic patients: postoperative 5-fluorouracil versus intraoperative mitomycin $\mathrm{C}$ antiproliferative therapy. Ophthalmic Surg 1995; 26: 73-7.

[14] Susanna R, Oltrogge EW, Carani JCE, Nicolela MT. Mitomycin as adjunct chemotherapy in congenital and developmental glaucoma. J Glaucoma 1995; 4: 151-7. 
[15] Giampani J; Borges-Giampani AS; Carani JC; Oltrogge EW; Susanna R. Efficacy and safety of trabeculectomy with mitomycin $C$ for childhood glaucoma: a study of results with long-term follow-up. Clinics 63(4): 421-6; 2008.

[16] Beck AD, Wilson WR, Lynch MG, Lynn MJ, Noe R. Trabeculectomy with adjunctive mitomycin C in pediatric glaucoma. Am J Ophthalmol 1998; 126: 648-57.

[17] Sidoti PA, Belmonte SJ, Liebmann JM, Ritch R. Trabeculectomy with Mitomycin-C in The Treatment of Pediatric Glaucomas. Ophthalmology 2000; 107: 422-9.

[18] Mandal AK, Walton DS, John T, Jayagandan A. Mitomycin C-augmented trabeculectomy in refractory congenital glaucoma. Ophthalmology 1997; 104: 996-1001.

[19] Miller MH, Rice NS. Trabeculectomy combined with $\beta$-irradiation for congenital glaucoma. Br J Ophthalmol 1991; 75: 584-90.

[20] Wahee US, Ritterband DC, Greenfield DS, Liebmamm JM, Sidoti AO, Ritch R. Blebrelated ocular infection in children after trabeculectomy with mitomycin C. Ophthalmology 1997; 104: 2117-20.

[21] Wallace DK, Plager DA, Synder SK, Raiesdana A, Helveston EM, Ellis FD. Surgical results of secondary glaucomas in childhood. Ophthalmology 1998; 105: 101-111.

[22] Wolner B, Liebmann JM, Sassani JW, Ritch R, Speaker M, Marmor M. Late bleb-related endophthalmitis after trabeculectomy with adjunctive 5-fluorouracil. Ophthalmology 1991; 98: 1053-60.

[23] Higginbotham EJ, Stevens RK, Musch DC, et al. Bleb-related endophthalmitis after trabeculectomy with mitomycin C. Ophthalmology 1996; 103: 650-6.

[24] Greenfield DS, Suver IJ, Miller MP, Kangas TA, Palmberg PF, Flynn HW. Endophthalmitis after filtering surgery with mitomycin. Arch Ophthalmol 1996; 114: 943-9.

[25] O'Malley Schotthoefer E; Yanovitch TL; Freedman SF. Aqueous drainage device surgery in refractory pediatric glaucomas: I. Long-term outcomes. AAPOS; 12(1): 33-9; 2008.

[26] Khan AO; Al-Mobarak F. Comparison of polypropylene and silicone Ahmed valve survival 2 years following implantation in the first 2 years of life. $\mathrm{Br} \mathrm{J}$ Ophthalmol; 93(6):791-4; 2009.

[27] Khan AO; Al-Mobarak F. Comparison of polypropylene and silicone Ahmed valve survival 2 years following implantation in the first 2 years of life. $\mathrm{Br} \mathrm{J}$ Ophthalmol 93(6): 791-4; 2009.

[28] Kay JS; Mitchell R; Miller J. Dilation and Probing of Schlemm's Canal and Viscocanalostomy in Pediatric Glaucoma. J Pediatr Ophthalmol Strabismus 48(1): 30-7; 2011.

[29] Noureddin BN; El-Haibi CP; Cheikha A; Bashshur ZF. Viscocanalostomy versus trabeculotomy ab externo in primary congenital glaucoma: 1-year follow-up of a prospective controlled pilot study. Br J Ophthalmol; 90(10): 1281-5; 2006.

[30] Kanski JJ. Iridocorneal dysgenesis. In Clinical Ophthalmology. ButterworthHeinemann, fifth edition, 248-252; 2003.

[31] Borges AS, Susanna Jr. R, Carani JCE, Betinjane AJ, Alward WL, Stone EM, Sheffield VC, Nishimura DY. Genetic analysis of PITX2 and FOXC1 in Rieger Syndrome patients from Brazil. J Glaucoma 11(1): 51-56; 2002.

[32] Shottenstein EM. Peters anomaly. In The Glaucomas. Ritch R, Shields MB, Krupin T. Mosby, second edition, 887-897; 1996.

[33] Weiss JS, Ritch R. Glaucoma in the Phacomatoses. In The Glaucomas. Ritch R, Shields MB, Krupin T. Mosby, second edition, 899-924; 1996.

[34] Bellows AR. Choroidal effusion during glaucoma surgery in patients with prominent episcleral vessels. Arch Ophthalmol 97: 793; 1979.

[35] Bost M. Congenital glaucoma and von Recklinghausen disease. Pediatrie 40:207; 1985. 


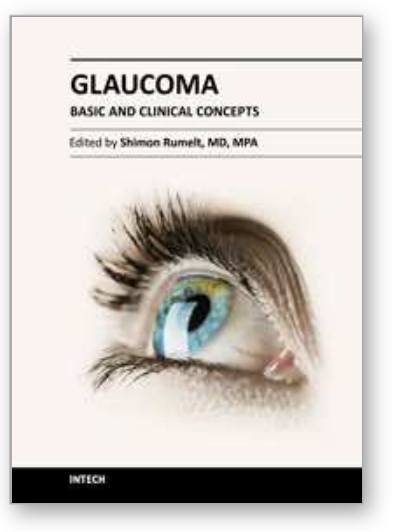

\author{
Glaucoma - Basic and Clinical Concepts \\ Edited by Dr Shimon Rumelt
}

ISBN 978-953-307-591-4

Hard cover, 590 pages

Publisher InTech

Published online 11, November, 2011

Published in print edition November, 2011

This book addresses the basic and clinical science of glaucomas, a group of diseases that affect the optic nerve and visual fields and is usually accompanied by increased intraocular pressure. The book incorporates the latest development as well as future perspectives in glaucoma, since it has expedited publication. It is aimed for specialists in glaucoma, researchers, general ophthalmologists and trainees to increase knowledge and encourage further progress in understanding and managing these complicated diseases.

\title{
How to reference
}

In order to correctly reference this scholarly work, feel free to copy and paste the following:

Jair Giampani Junior and Adriana Silva Borges Giampani (2011). Congenital Glaucoma, Glaucoma - Basic and Clinical Concepts, Dr Shimon Rumelt (Ed.), ISBN: 978-953-307-591-4, InTech, Available from: http://www.intechopen.com/books/glaucoma-basic-and-clinical-concepts/congenital-glaucoma

\section{INTECH}

open science | open minds

\author{
InTech Europe \\ University Campus STeP Ri \\ Slavka Krautzeka 83/A \\ 51000 Rijeka, Croatia \\ Phone: +385 (51) 770447 \\ Fax: +385 (51) 686166 \\ www.intechopen.com
}

\author{
InTech China \\ Unit 405, Office Block, Hotel Equatorial Shanghai \\ No.65, Yan An Road (West), Shanghai, 200040, China \\ 中国上海市延安西路65号上海国际贵都大饭店办公楼405单元 \\ Phone: +86-21-62489820 \\ Fax: +86-21-62489821
}


(C) 2011 The Author(s). Licensee IntechOpen. This is an open access article distributed under the terms of the Creative Commons Attribution 3.0 License, which permits unrestricted use, distribution, and reproduction in any medium, provided the original work is properly cited. 